\author{
Héctor Rato Martín ${ }^{1}$ y Gaspar Fernández Cuesta \\ Departamento de Geografía. Universidad de Oviedo
}

\title{
El Plano de población y ensanche de la villa de Navia de 1934
}

\section{RESUMEN}

La villa de Navia contó a mediados de los años treinta con un ambicioso proyecto de ensanche y reforma interior. En el presente artículo se describen las características de dicho proyecto, incluyendo una reconstrucción del plano, al no conservarse el original.

\section{RÉsuMÉ}

Le Plan de ville et extension urbaine de la ville de Navia de 1934.- La ville de Navia disposait d'un ambitieux projet d'extension urbaine et réaménagement dans les années 30 du dernier siècle. Cet article décrit les caractéristiques de cet projet, en incluant une reconstruction du plan qui vise á montrer la représentation de l'original (celui-ci n'existant plus).

\section{LOS ORÍGENES DE NAVIA}

$L$ a fundación de la puebla de Navia tuvo lugar hacia 1270 en el contexto de la política repobladora del norte peninsular llevada a cabo por el monarca castellano Alfonso $\mathrm{X}^{2}$. El emplazamiento seleccionado fue una pequeña elevación en la margen derecha de la ría de Navia, cerca de su desembocadura, sobre la que se levantó un poblado de plano notablemente regular. Esto induce a pensar que, al igual que en otros casos similares, fue trazado conforme a un plan preconcebido siguiendo las instrucciones de un departidor real. El funcionario regio también debió

\footnotetext{
${ }^{1}$ Becario predoctoral para la Formación en Investigación y Docencia, Ficyt, Gobierno del Principado de Asturias, expediente BP12-125.

${ }^{2}$ Con anterioridad a la fundación de la puebla existía en el entorno del lugar un asentamiento portuario, cuya localización exacta no está determinada (Ruiz de la Peña, 1981, pp. 105-106).
}

Abstract

The Street and urban extension map of the town of Navia in 1934.The town of Navia had in the middle thirties an ambitious project of urban extension and internal reform. Characteristics of the project are described in this article, including a map's reconstruction as the original is no longer preserved.

\section{Palabras Clave/Mots Clé/Keywords}

Navia, villa costera, plano, ensanche.

Navia, ville côtière, plan, projet d'extension urbaine.

Navia, coastal town, street map, urban extension project.

de marcar el trazado de la cerca (Ruiz de la Peña, Beltrán Suárez y Álvarez Fernández, 2006, p. 132), de 580 metros de longitud, cuya construcción se prolongó quizá hasta el siglo xIv. Dentro del recinto murado los edificios más destacados eran la iglesia parroquial, el hospital de enfermos y peregrinos, el abasto de carnes y el alfolí de sal (Martínez Fernández, 1986, pp. 116-118).

Las ocupaciones mayoritarias de la población eran la pesca, tanto fluvial como marítima, y el comercio. Una actividad esta última desarrollada fundamentalmente por vía marítima dada la precariedad de las vías de comunicación terrestres, con una red caminera poco desarrollada $\mathrm{y}$, sobre todo, en estado calamitoso.

La villa gozó de una cierta prosperidad económica durante la Baja Edad Media, que se prolongó durante la Edad Moderna, pese a lo cual nunca pudo llegar a competir con los más cercanos y dinámicos puertos de Luarca y Puerto de Vega (Méndez García, 1992, p. 278; Murcia 
FIG. 1. La apertura del puente sobre la ría del Navia, en 1868, permitió unir por primera vez sus dos orillas, hasta entonces conectadas por un servicio de barca. Al fondo de la imagen El Espín (Coaña), que tras la inauguración de esta infraestructura acogió algunos talleres industriales. Anónimo. Muséu del Pueblu d'Asturies.

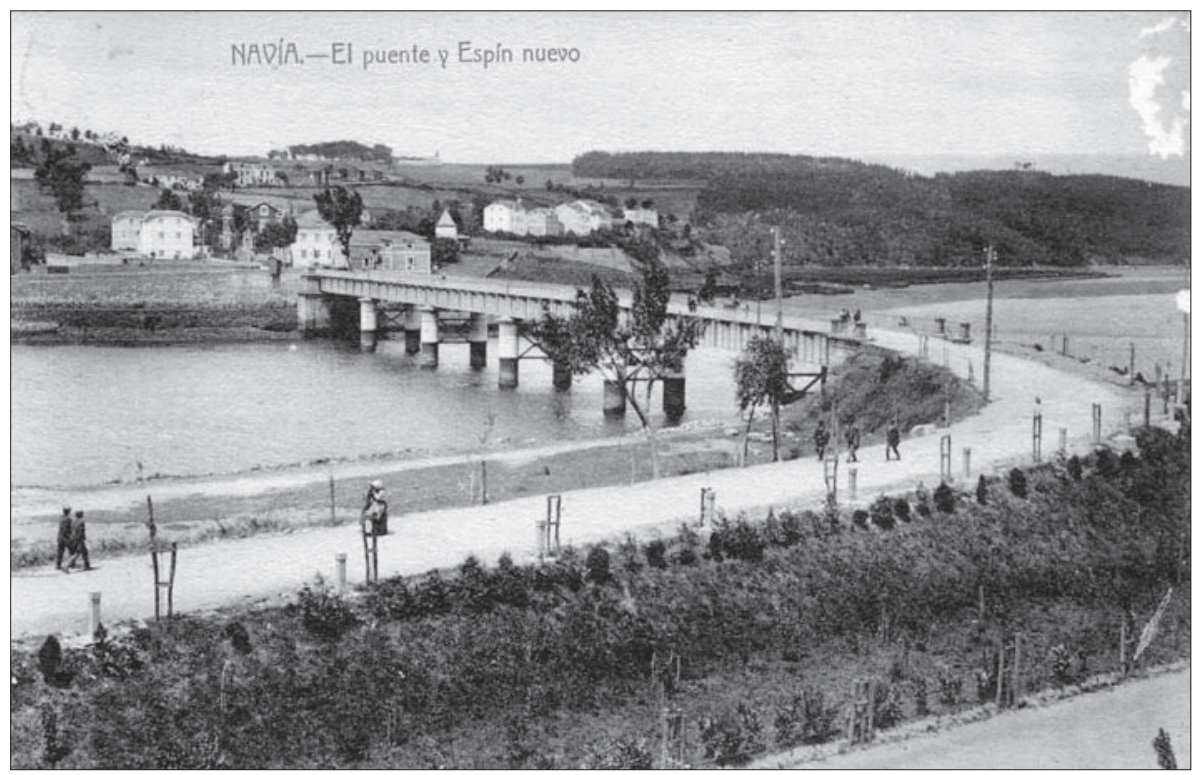

Navarro, 1981,p. 407). Menos aún a partir del siglo XVIII, cuando se redujeron considerablemente el número de capturas pesqueras y las entradas y salidas de barcos en el puerto. Esto se debió al sometimiento de los marineros a las levas, al incremento en el precio de la sal (Peribáñez Caveda, 1992, pp. 163-177) y a la colmatación de la barra de la entrada en la ría (Fernández Méndez, 2002, p. $30)$, entre otras razones.

La situación de atonía se prolongó hasta las últimas décadas del siglo xIx, momento en el que pudo revertirse gracias al impulso generado por la mejora general de las infraestructuras de transporte.

En el ámbito del transporte terrestre, el hito trascendental fue la construcción del puente sobre la ría, inaugurado en 1868 (Acevedo y Huelves, 1900, p. 332). De forma inmediata permitió la ansiada conexión entre las dos orillas y, a más largo plazo, una vez inaugurado el tramo de carretera Oviedo-Villalba (Murcia Navarro, 1981, pp. 250-251), que la villa fuera atravesada por el principal eje de carreteras entre Asturias y Galicia. Su posición también se vio reforzada tras la apertura de las carreteras Navia-Boal, Navia-Villayón y el Espín-Grandas de Salime (Méndez García, 1992, p. 278), que ayudaron a consolidarla como cabecera comarcal de todo el valle inferior del río Navia.

En lo que respecta a las comunicaciones marítimas, los tráficos se vieron favorecidos con la construcción de la nueva dársena (1897), que fue ampliada poco después (1905) (Martínez Fernández, 1967, pp. 135-136), pues las obras permitieron mejorar las características del puerto (superficie de maniobra, líneas de atraque, muelles y calado) y adaptarlas a las necesidades de los barcos modernos, cada vez más grandes.

También fueron determinantes para el estímulo económico los capitales retornados de América a través de los indianos, que, tras hacer fortuna en las tierras de ultramar, se establecieron en Navia. Éstos constituyeron el germen de una pequeña burguesía local y se convirtieron rápidamente en el principal agente impulsor de la transformación urbana de la villa (Murcia Navarro, 1981, pp. 407-408). Valiéndose de sus recursos económicos, pero también de sus influyentes posiciones en el Gobierno municipal, promovieron y ejecutaron diferentes operaciones de reforma interior y de expansión urbana bien adaptadas a sus necesidades y a sus gustos, que con el tiempo dieron lugar a un modelo urbano de características bien distintas al heredado del Antiguo Régimen.

La reforma interior tuvo como primera y más importante iniciativa el derribo de la antigua cerca, lo que permitió eliminar el corsé que dificultaba el crecimiento extramuros de la villa, especialmente hacia la ría. Las obras se iniciaron a principios de la década de 1830 con la demolición del arco de la puerta de la villa (Martínez Fernández, 1963 , p. 122, n. 3), que posteriormente fue eliminada por completo y sustituida por un paseo (Acevedo y Huelves, 1900 , p. 332), pero no concluyeron hasta el año 1888 . También fue derruido el viejo templo parroquial, que fue reemplazado por una nueva iglesia de mayores dimensiones construida fuera del antiguo recinto amurallado; el espacio dejado vacante sirvió para ampliar la plaza Mayor. 


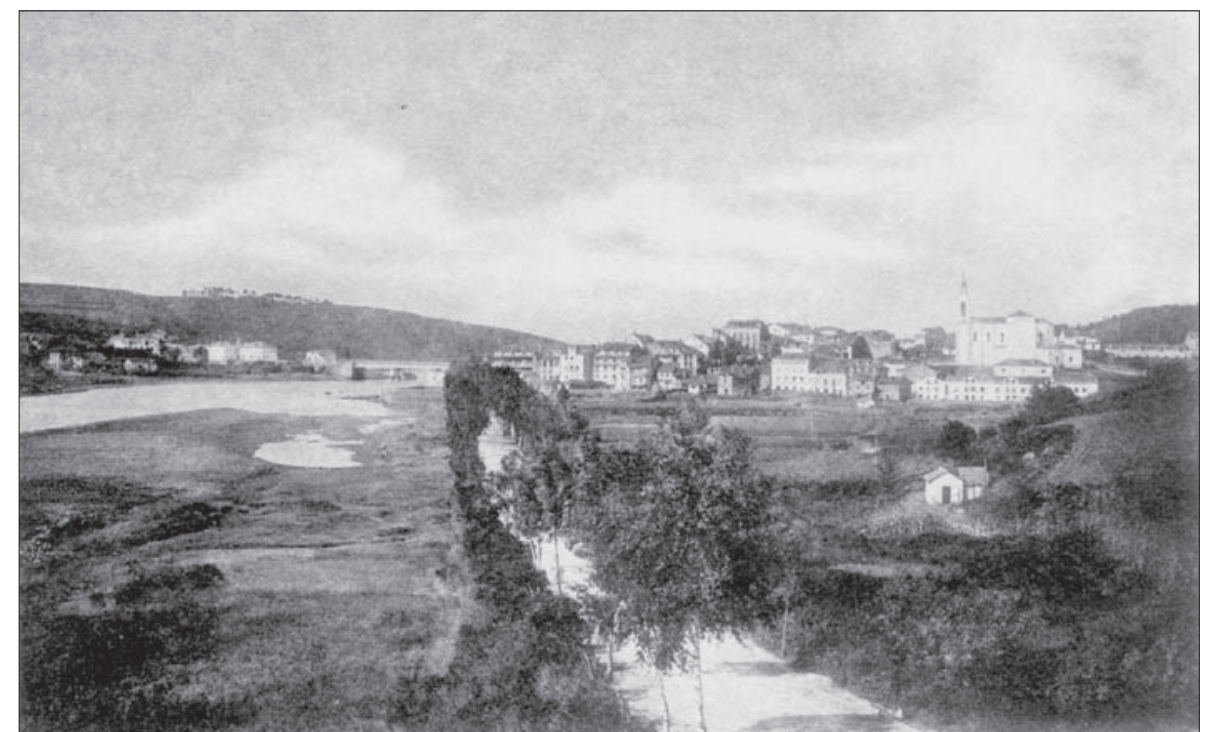

FIG. 2 Carretera de Oviedo en torno a 1900. Esta carretera sirvió como principal eje director del crecimiento urbano de la villa, una vez saneadas las marismas de sus márgenes. Sobre el espacio llano a la derecha de la imagen diseñaría el ingeniero José Martín Elvira la zona sur de su proyecto de ensanche. Al fondo destaca la figura del nuevo templo religioso inaugurado en 1895 en sustitución de la antigua iglesia parroquial. Fotografía de Octavio Bellmunt incluida en Acevedo y Huelves (1900, p. 331).
Finalmente, se llevaron a cabo obras de prolongación y ensanchamiento de varias calles y otros espacios públicos, para lo que fue necesario derribar varios edificios antiguos (Martínez Fernández, 1965, pp. 162-169).

La expansión urbana, por su parte, se concentró, durante la última década del siglo xIX y las primeras del XX, a lo largo de la nueva carretera de Oviedo, construida sobre los terrenos marismeños situados entre la vieja cerca y la ría ${ }^{3}$. Dado su carácter, la utilización y parcelación de estos terrenos requirió de importantes obras previas de desecación que fueron realizadas mediante concesión por particulares ${ }^{4}$. En el noroeste, en la salida hacia Galicia, se construyó el paseo ajardinado del Muelle (avenida Ramón Valdés) y varios bloques de viviendas de dos o tres plantas dotados de bajos comerciales, lo que contribuyó a convertir a esta zona en el nuevo centro urbano (Méndez García, 1993, p. 248). En el sur, sobre los terrenos ganados a las marismas, pero también en la margen oriental de la carretera a Oviedo, se levantaron varios edificios exentos de cierto porte que formaron un nuevo barrio caracterizado por la elevada calidad de la edificación y el bajo grado de ocupación del suelo (Méndez García y Morales Matos, 1991, p. 557).

\footnotetext{
3 Algunas fuentes señalan que este crecimiento urbano pudo realizarse al amparo de un proyecto de alineación y ensanche realizado en 1875 por Benigno Rodríguez y González. Sin embargo, al no haber sido localizado el expediente, no podemos confirmarlo. Martínez Fernández (1967, p. 121).

${ }_{4}$ El principal promotor del relleno de las marismas fue el notario Rafael Fernández Calzada. <http://www.occidente.com/navia/villa.htm>. [Consulta: 2504-2016.]
}

Todas estas actuaciones, junto con la instalación de alumbrado eléctrico, la construcción de la red de alcantarillado y de agua potable, el pavimentado de algunas calles y la apertura de un nuevo cementerio más alejado de la población (Martínez Fernández, 1965, pp. 162-169), otorgaron a Navia un cierto halo de modernidad que era evidente a principios de la década de 1930. Un momento en el que la villa había revitalizado su economía, merced al creciente tráfico portuario (Fernández Méndez, 2002, pp. 60-62), a una incipiente actividad industrial y a ser la cabecera comarcal de un espacio que desbordaba sus reducidos límites municipales.

Es esta la coyuntura en la que surgió el Plano de población y ensanche de la villa de Navia de 1934, encargado por el Consistorio con el propósito de diseñar y dirigir el futuro crecimiento de la villa, así como de corregir algunos de los problemas existentes derivados de la estructura urbana de la ciudad heredada.

\section{EL MARCO LEGAL}

A partir de mediados del siglo XIX, la llegada de las primeras manifestaciones industriales produjo cambios muy profundos en el modelo de ciudad característico del Antiguo Régimen. Por un lado, se aceleró de forma muy notable el ritmo del crecimiento urbano y simultáneamente adquirieron cada vez mayor protagonismo las nuevas instituciones nacidas con el estado liberal en la planificación de la forma urbana. Así, en las últimas décadas del siglo XIX el Estado central promulgó distintas 
FIG. 3. Tras la desecación de las marismas, a finales del siglo XIX comenzó a consolidarse al norte de la localidad el nuevo centro urbano que acogería algunos edificios de varias plantas en cuyos bajos se instalaron diversos establecimientos comerciales y de ocio. El carácter burgués de este espacio se vio refrendado con la apertura del paseo del Muelle, que pese a su cercanía al puerto aportó una cierta calidad ambiental. Enrique Gómez. Muséu del Pueblu d'Asturies.

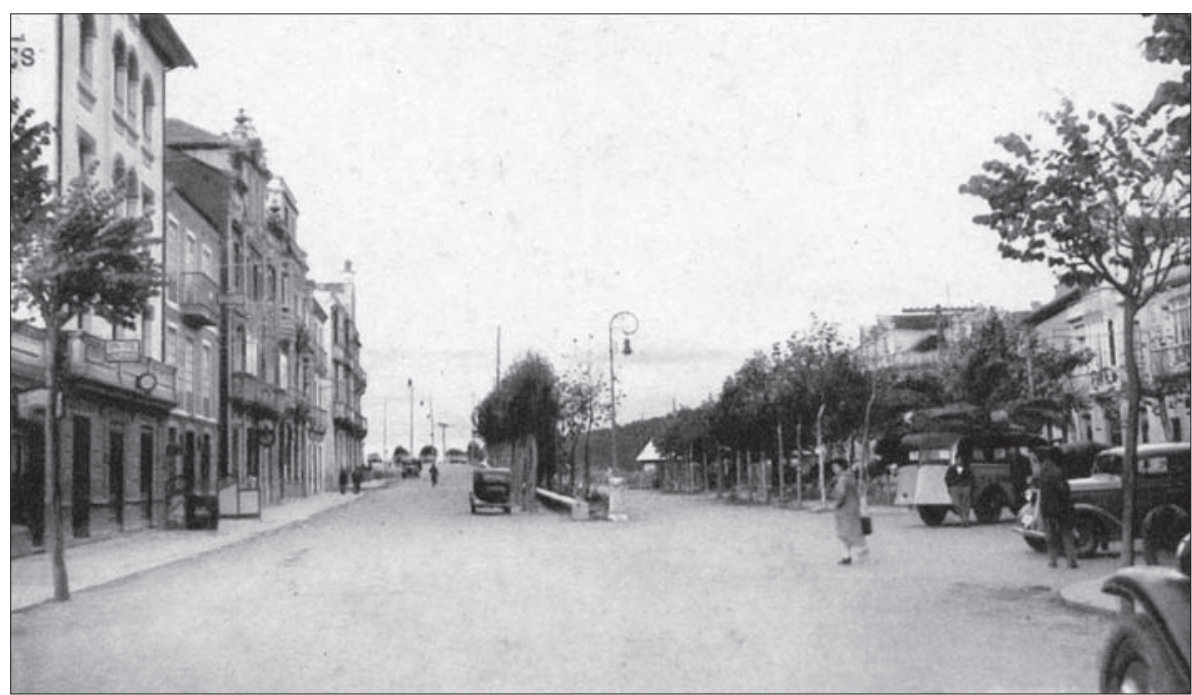

leyes y ordenanzas destinadas a regular, definir y concretar la forma en la que debían de expandirse los núcleos urbanos. Las más relevantes fueron las leyes de ensanche de 1864,1876 y 1892 , a cuyo amparo se redactaron la mayor parte de los proyectos de expansión urbana aprobados con anterioridad a 1920 .

En Asturias, las poblaciones que aprobaron proyectos de ensanche durante este tiempo fueron generalmente las que gozaron de mayor dinamismo económico ${ }^{5}$, como Gijón, Avilés, Mieres o Langreo. Ahora bien, también dispusieron de este tipo de documento algunas cabeceras comarcales que, como Llanes o Colombres, contaban con una acreditada colonia de indianos. Fueron éstos, en efecto, quienes con su influencia política y su poder económico impulsaron y financiaron el levantamiento de planos y la redacción de proyectos de ampliación urbana. Desgraciadamente, la mayor parte de estos proyectos o no pasaron del papel o tuvieron un grado de ejecución muy limitado; bien porque sus previsiones eran desmesuradas y conllevaban un coste económico inasumible para los ayuntamientos, bien por la oposición de los propietarios del suelo.

Las leyes de ensanche prolongaron su vigencia hasta 1924, año en el que bajo la dictadura de Primo de Rivera se promulgó el Estatuto Municipal, un documento de enorme trascendencia en la historia urbana de España. La nueva normativa transfería desde el Estado a los mu-

\footnotetext{
5 La excepción la constituye el proyecto de ensanche de Ribadesella, de Darío de Regoyos Molenillo, aprobado en 1855 con el objetivo de planificar la ocupación de los terrenos ganados al mar tras la construcción del nuevo puerto.
}

nicipios las competencias urbanísticas y en su reglamentación incorporaba de forma sintética buena parte de las leyes anteriores sobre urbanismo (Terán, 1999, pp. 170171). Además, obligaba a los núcleos urbanos que superasen los diez mil habitantes y hubiesen crecido durante la década anterior más de un veinte por ciento a redactar proyectos de ensanche ${ }^{6}$.

En Asturias la obligación impuesta por el Estatuto tuvo consecuencias urbanísticas si cabe mayores que en otros lugares de España, pues algunas capitales municipales utilizaron las variables demográficas de sus concejos para justificar la elaboración de proyectos de ensanche para ellas mismas. Fue el caso de Pola de Siero (1.648 habitantes en la villa y más de 27.000 en el concejo) (Quirós Linares, 1985, pp. 95-96), o el de Navia (1.129 y 7.000 , habitantes respectivamente $)^{7}$.

\section{EL CONCURSO DE ADJUDICACIÓN ${ }^{8}$}

El ensanche de Navia, objeto de interés de este artículo, comenzó a gestarse el 21 de setiembre de 1932, cuando la Corporación municipal convocó un concurso

\footnotetext{
6 Reglamentos para la ejecución del Estatuto Municipal aprobados por los Reales Decretos de 2, 10 y 14 de julio y 22 y 23 de agosto de 1924 (1924, pp. 66-67).

7 En la memoria del proyecto no se hace referencia al Estatuto Municipal, pero parece razonable pensar que la nueva normativa influyera decisivamente sobre el Ayuntamiento a la hora de tomar la decisión.

8 AMN 557.59-Expediente de contratación para la redacción del plano de población y ensanche o plan general de ordenación urbana de la villa de Navia (1932-36).
} 


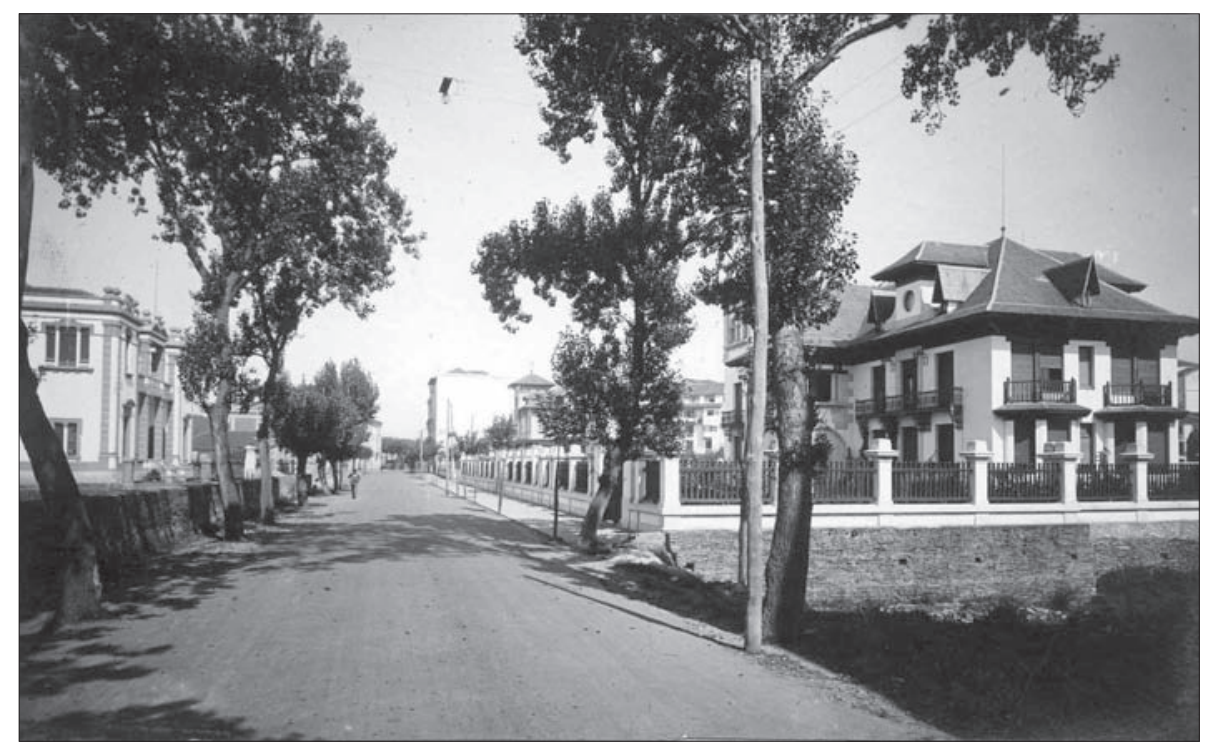

FIG. 4. A diferencia de lo ocurrido al norte, los terrenos obtenidos tras la desecación de las marismas meridionales fueron ocupados por una edificación más abierta, en la que destacaban algunos palacetes. Los de Luis Arias y de Pérez Casadoiro, al este de la carretera de Oviedo, tenían carácter residencial; otros, como el Casino, inaugurado en 1923 enfrente de los anteriores, estaban destinados al ocio. L. Roisin. Muséu del Pueblu d'Asturies.

para levantar un Plano de población y ensanche de la villa de Navia. El ganador debería realizar un plano que incluyese propuestas tanto de reforma interior como de nuevas alineaciones que dirigieran la futura expansión urbana. La convocatoria establecía los límites geográficos del espacio que debería incluir el plano y su escala (1:500), así como la documentación que debería de acompañarlo (memoria y perfiles longitudinales) y la duración de la fase de redacción del mismo (cinco meses).

Al concurso concurrieron los ingenieros Eugenio Guallart y Martínez, vecino de Mieres, y José Martín Elvira, residente en Doiras (Boal). La mejor oferta fue la presentada por el primero, quien solicitaba por la redacción del proyecto 7.450 pesetas, una cifra bastante menor que la del segundo, que ascendía a 9.000 pesetas. Ahora bien, estas cantidades no fueron determinantes para la adjudicación, pues Eugenio Guallart se retiró al haberle surgido «otros compromisos que me impedían la realización de aquel trabajo en las fechas previstas». Ante esta circunstancia el Ayuntamiento, en primera instancia, declaró el concurso desierto y, más tarde, se lo concedió a José Martín Elvira, si bien por una suma de 8.000 pesetas, mil menos de las que éste había solicitado inicialmente.

Realizada la adjudicación, el ingeniero inició las tareas de redacción del proyecto, pero no pudo terminarlo en el plazo previsto; según argumentó, debido a las condiciones meteorológicas adversas y también a la necesidad de cumplir con otras obligaciones. Ante las razones expuestas el Ayuntamiento le concedió una prórroga y el proyecto fue finalmente presentando y aprobado por el Consistorio el 28 de febrero de 1935.

\section{EL PROYECTO}

Tal y como se pedía en las bases del concurso de adjudicación, el proyecto presentado por José Martín Elvira contenía un plano de la población y una memoria descriptiva. Desgraciadamente el plano no ha llegado hasta nosotros, pero sí la memoria y los perfiles longitudinales, así como toda la documentación administrativa generada en el proceso de adjudicación, que se conservan en el Archivo Municipal.

A partir de la documentación preservada sabemos que en el plano original se representaba la villa y su entorno; un espacio delimitado por la ría de Navia, la ladera del monte de Andés, la carretera de la Colorada y el camino de San Roque a Buenavista. En total cubría una superficie ligeramente superior a las cinco mil áreas sobre la que se dibujaron las propuestas de reforma interior y nuevas alineaciones. Como es obvio, la pérdida del plano original supone un grave perjuicio para conocer con exactitud esas propuestas; ahora bien, la información contenida en la memoria y en los perfiles longitudinales, con los puntos en los que se producen las intersecciones de las calles, nos ha permitido reconstruirlo. Aun sabiendo que

\footnotetext{
9 AMN, caja 554.7. Expediente de plano de población y ensanche o plan general de ordenación urbana de la villa de Navia.
} 
el plano obtenido difícilmente puede ser una copia exacta del original, tenemos la convicción de que responde con bastante precisión al diseñado por Martín Elvira.

A partir del plano que hemos dibujado podemos conocer las principales propuestas realizadas por el ingeniero, que se recogían en la memoria bajo los epígrafes «Modificaciones en el casco de la población» y «Ensanche».

\section{ModifiCACIONES EN El CASCO DE LA POBlaCióN}

Según consta en la memoria, no llegó nunca a plantearse una modificación sustancial de la trama urbana preexistente, pues consideraba más apropiado y realista plantear unas pocas reformas que no entrañaran excesivos costes y pudieran ser asumidas por las exhaustas arcas municipales. Las actuaciones propuestas se reducían, por tanto, a la alineación de algunas calles, al derribo de varias casas que amenazaban ruina o eran antihigiénicas y a la división de varias manzanas de grandes dimensiones.

La existencia de dos manzanas de gran tamaño era considerada la causa de que no se hubiese edificado en las parcelas que se encontraban en la parte interior de las mismas, pues al no disponer de salida directa a los viales carecían del más mínimo interés edificatorio. Para hacerlas más atractivas a los promotores inmobiliarios $\mathrm{y}$, en consecuencia, que pudieran ocuparse, Martín Elvira proponía la apertura de nuevas calles que dividieran las manzanas originales e hicieran accesibles los solares interiores. Una de las manzanas afectadas era la delimitada por las calles Calzada, Galán y García Hernández y avenida de Ramón Valdés, que se dividiría en tres con el trazado de dos nuevos viales. La operación se acompañaría además con la apertura de un jardín triangular que mejoraría las condiciones del entorno. La otra manzana, cuyo perímetro estaba marcado por las calles Argentina, San Francisco, Rivero y Regueral, se dividiría en cuatro, lo que implicaba la apertura de tres nuevas travesías, una de ellas resultado de la ampliación de un callejón preexistente.

Otras propuestas de reforma interior eran de mucha menor envergadura y se limitaban a rectificar y ensanchar varias calles y plazas, así como a corregir el perfil de algunas esquinas. Entre ellas las más destacables, por su trascendencia en el plano, fueron la ampliación de la carretera de Puerto de Vega, a la que se otorgaba una anchura de doce metros de ancho; el recrecido de la plaza Mayor, y la rectificación del trazado de la calle Párroco Trueba y de la plaza de los Cerdos, que implicaban el derribo de tres casas y varias cuadras.

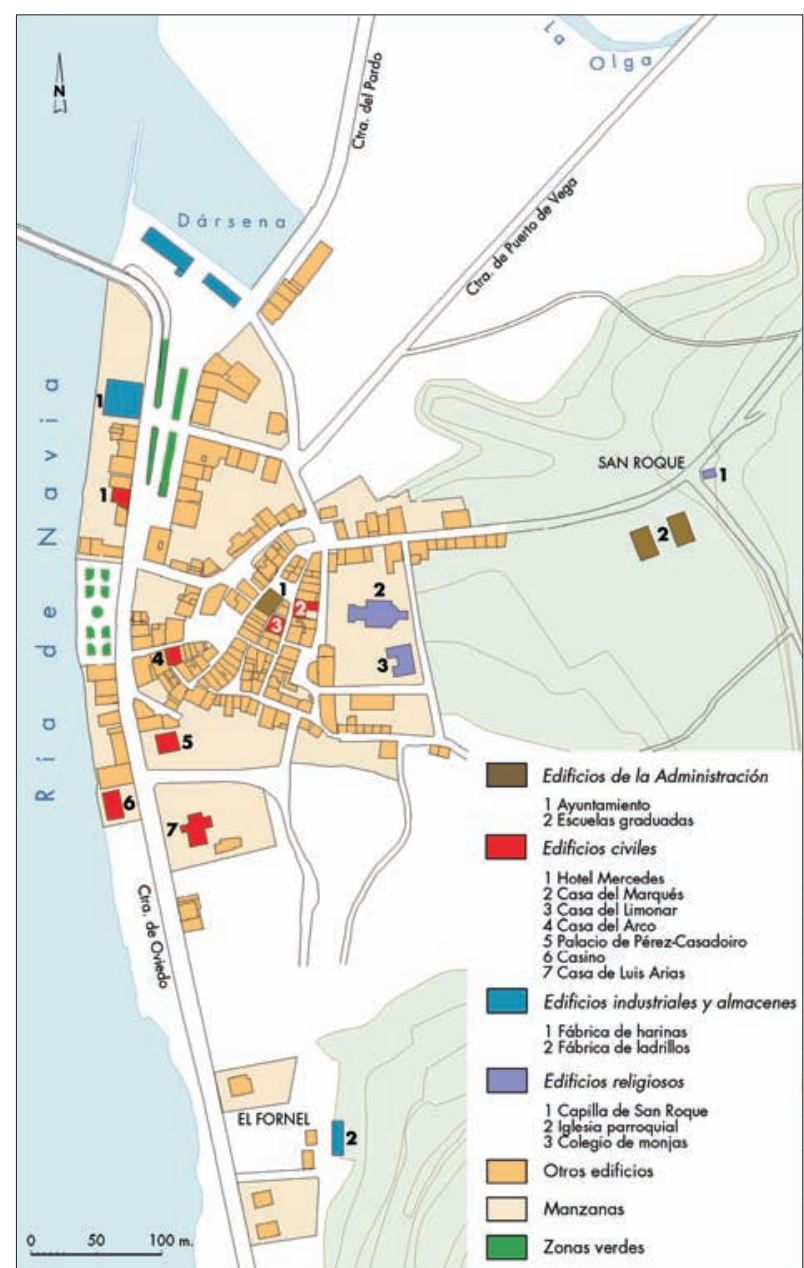

FIg. 5. Plano de la villa de Navia hacia 1935. Elaboración propia a partir del plano de Mariano Luiña de 1917 incluido en Junceda (1936); el plano de Efrén García de 1945 incluido en García Fernández (1979); cartografía catastral actual; mapa topográfico del Principado de Asturias escala 1:5.000 (2005-2006), hojas 110406 y 110407; fotografía del año 1945, vuelo americano serie A, CECAF, fotograma 6454 (copia facilitada por el Observatorio del Territorio, Departamento de Geografía de la Universidad de Oviedo); fotografía del año 1957, serie $\mathrm{H}$, CECAF, fotograma 864 (copia facilitada por el Observatorio del Territorio, Departamento de Geografía de la Universidad de Oviedo); Tecnia (2015) y Álvarez Suárez y Gámez (1923)

\section{El ENSANCHE}

El ensanche, con las nuevas alineaciones propuestas para dirigir el futuro crecimiento de la localidad, era la parte esencial del proyecto. Como puede comprobarse en la documentación, el proyecto planteaba incorporar al casco urbano una superficie de 1.230 áreas, suficiente según los cálculos realizados para absorber el crecimiento 


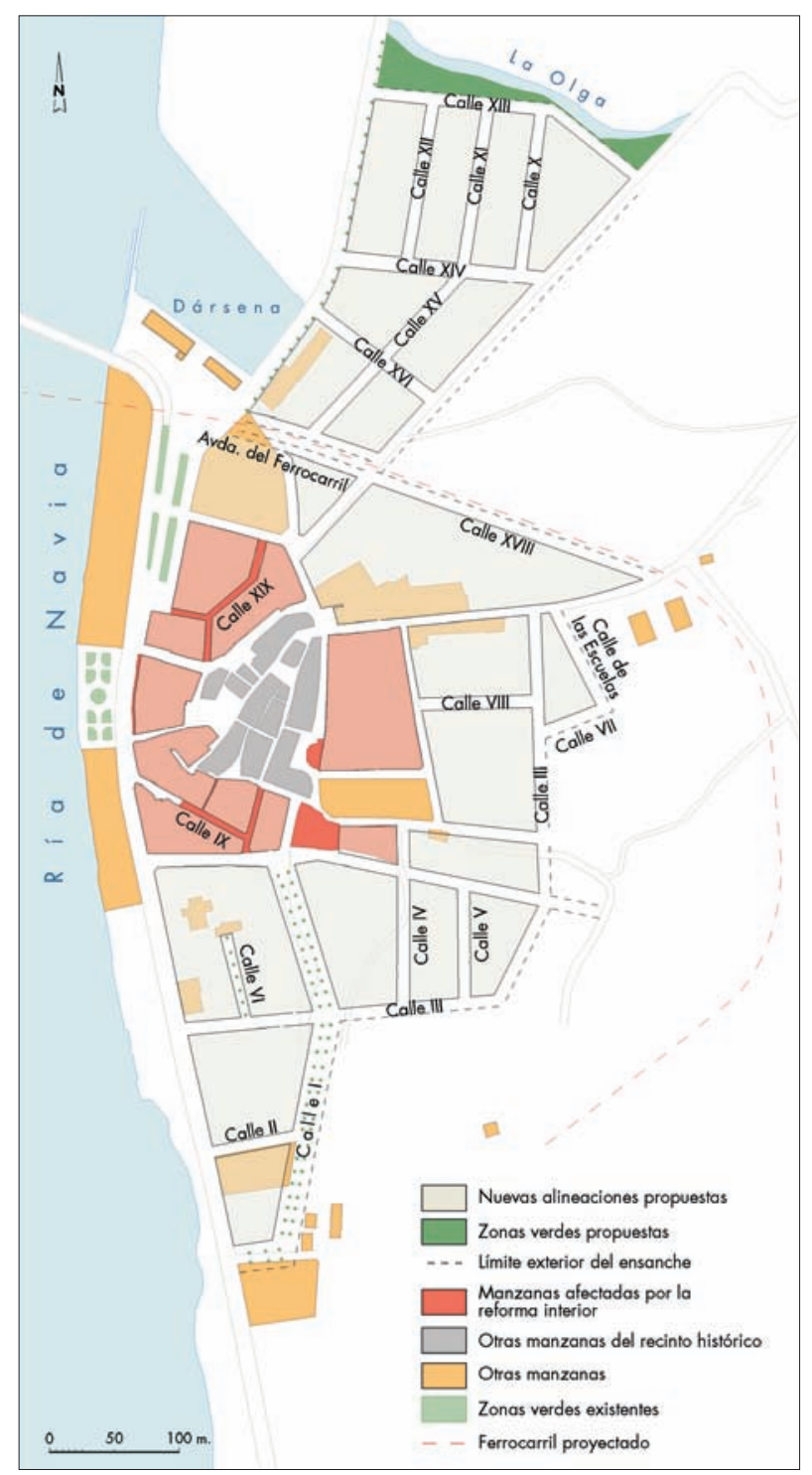

FIG. 6. Proyecto de ensanche y reforma interior de Navia de 1934. Elaboración propia a partir de la memoria y los perfiles longitudinales del Plano de población y ensanche de la villa de Navia (1934); plano de Mariano Luiña de 1917 incluido en Junceda (1936); plano de Efrén García de 1945 incluido en García Fernández (1979); cartografía catastral actual; mapa topográfico del Principado de Asturias escala 1:5.000 (2005-2006), hojas 110406 y 110407; fotografía del año 1945, vuelo americano serie A, CECAF, fotograma 6454 (copia facilitada por el Observatorio del Territorio, Departamento de Geografía de la Universidad de Oviedo); fotografía del año 1957, serie H, CECAF, fotograma 864 (copia facilitada por el Observatorio del Territorio, Departamento de Geografía de la Universidad de Oviedo).

de Navia durante medio siglo. Teniendo en cuenta que por aquel entonces la superficie urbana era de 689 áreas, la ejecución del proyecto supondría multiplicar por tres el espacio existente en el momento de su aprobación. Una superficie que puede parecer desmesurada, como así resultó finalmente, pero que el autor justificaba con unas previsiones demográficas que le llevaban a pensar que la población pudiera alcanzar el umbral de los 2.959 habitantes. Cifra, sin duda, exagerada teniendo en cuenta que en el medio siglo precedente la población no había conseguido incrementarse ni tan siquiera en seiscientos habitantes (Murcia Navarro, 1981, pp. 276-277).

Martín Elvira consideraba que la planificación del crecimiento espacial debería regirse por el mismo posibilismo económico que había utilizado para diseñar la reforma interior; razón por la cual renunció a la trama ortogonal ${ }^{10}$ y eligió otra mucho menos regular, adaptada a la red de caminos y al parcelario preexistentes. De esta forma minimizaba el número de propietarios afectados por las expropiaciones y, consecuentemente con ello, el coste que tendría para el ayuntamiento la aplicación del plan. Con la misma finalidad trató de restringir al máximo el número de edificios afectados, reduciéndolos en este caso a un pequeño número de casas emplazadas en la confluencia del ensanche con el casco histórico y a algunos almacenes situados en la zona de la dársena.

Un segundo condicionamiento que tuvo en cuenta el autor para definir la trama del ensanche fue el trazado previsto para la línea del ferrocarril Ferrol-Gijón a su paso por la villa. Según el proyecto ferroviario, las vías circunvalarían el casco urbano a una cierta distancia del mismo por su vertiente oriental y septentrional, describiendo un gran semicírculo. La existencia del propio ferrocarril ya dificultaba el diseño del nuevo plano, pero su trazado implicaba además la construcción de varias obras de importancia. La vía férrea discurriría por una trinchera en el entorno de la carretera de La Colorada, para circular a continuación por un terraplén hasta el cruce con la carretera de Puerto Vega. En ese punto arrancaría un viaducto que atravesaría la dársena y la ría.

Ante la dificultad que encerraba abrir calles transversales al ferrocarril sin hacer obras de fábrica o darles excesiva pendiente, el ingeniero trazó una calle paralela a la vía férrea sobre el terraplén, la número xvIII. Este vial conectaría las carreteras de La Colorada y Puerto de Vega y permitiría desviar parte del tráfico de las calles del centro. Como prolongación diseñó una avenida de 25 metros de ancho (denominada «avenida del Ferrocarril») hasta el

\footnotetext{
${ }_{10}$ Para José Martín Elvira el trazado irregular del plano servía también para romper «la monotonía que resulta con las poblaciones trazadas en forma de cuadrícula».
} 


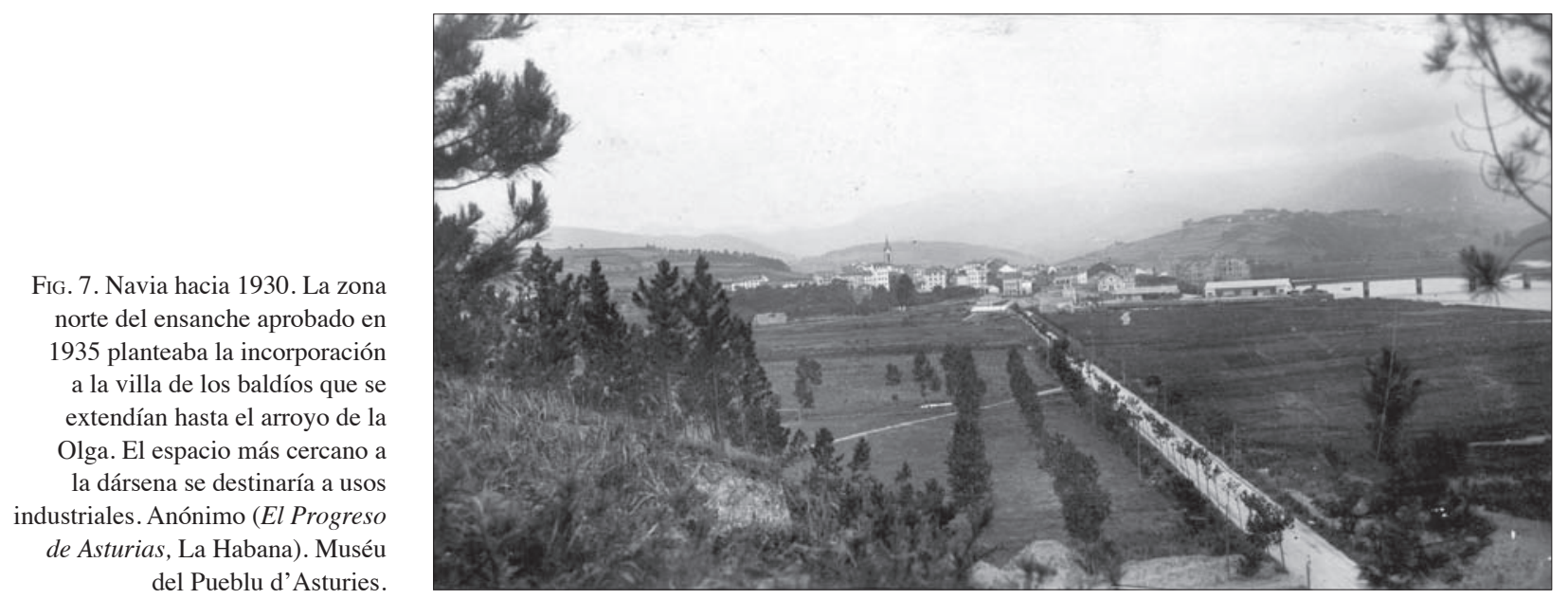

entorno de la dársena, por el eje de la cual discurriría el viaducto ferroviario. Por último, también se menciona la posibilidad de hacer futuras modificaciones en el trazado de algunas de las calles propuestas en función de la localización de la estación, aún por concretar.

En cualquier caso, la incidencia del ferrocarril sobre la trama fue tan grande que finalmente se planteó la división del ensanche en dos unidades de desigual tamaño: la norte, de 427,5 áreas de superficie, y la sur, que ocuparía 802,5 áreas.

\section{A) El ensanche norte}

Comprendía el espacio situado al norte de la línea ferroviaria y también del casco urbano existente. Estaba delimitado, a poniente y levante, por las carreteras del Pardo y Puerto de Vega, respectivamente, y al norte, por el arroyo de la Olga. La existencia de este curso fluvial obstaculizaba la expansión urbana más allá del mismo, puesto que su relleno y canalización con tuberías eran muy costosos. Sí se desecarían, en cambio, los cauces secundarios del arroyo, cuyas obras de ejecución no eran excesivamente onerosas y permitirían ganar, además, terrenos para trazar el vial más septentrional del ensanche y el jardín que marcaría el confín del mismo en esta dirección.

En lo referente a los usos, Martín Elvira planteaba para esta zona una clara diferenciación de los mismos. El espacio situado al sur de la calle xIV, el más próximo a la dársena portuaria, en el que ya existían algunas fábricas y almacenes, se reservaba para usos industriales. Por su parte, el situado al norte, más alejado de las actividades portuarias y con una trama formada por calles orientadas de norte a sur que facilitaba la luminosidad de las viviendas, se destinaba a usos residenciales. Más concretamente, la memoria señalaba la idoneidad de las manzanas para albergar viviendas unifamiliares («hotelitos») con jardín.

\section{B) El ensanche sur}

Esta parte del ensanche, encorsetada en su vertiente oriental por la proyectada línea del ferrocarril, estaba compuesta por las manzanas proyectadas para dirigir la expansión de la villa hacia levante y hacia el sur. En la trama propuesta dos calles destacaban por encima de las demás, la número i y la número III. La primera, de 21 metros, era la más ancha, tenía una disposición N-S y estaría arbolada en su parte central a lo largo de todo su recorrido. La número III, aunque de menor anchura, era la más larga de las proyectadas; uniría la carretera de Oviedo con la de La Colorada sin atravesar el centro de la población y serviría de ronda exterior tanto por el sur como por el este. Otras calles del ensanche surgían de la prolongación de algunos viales ya existentes (San Francisco, avenida de la Argentina...), por lo que servían también de engarce entre aquél y la ciudad histórica.

De los viales proyectados surgieron doce nuevas manzanas, cuya principal característica era la heterogeneidad. Su adaptación a los caminos preexistentes es la causa de que no hubiese dos iguales y de que sus formas y tamaños fuesen muy dispares. Las modificaciones sobre las manzanas preexistentes fueron de escasa relevancia; lo más llamativo fue el derribo de unas casas situadas entre las calles Argentina, San Francisco y Párroco Trueba, que desaparecerían con el objeto de abrir una nueva plaza. 
La memoria del proyecto no hace ninguna referencia a usos no residenciales en esta zona, con la única excepción de la que se refiere a la posible instalación de un hospital en una manzana especialmente adecuada para ello por encontrarse a resguardo de los vientos.

\section{EL LEGADO DEL PROYECTO}

El estallido casi inmediato de la guerra civil y el estancamiento económico sufrido por la villa con posterioridad al conflicto son las causas más probables del escaso grado de materialización del proyecto en los años siguientes a su aprobación, como también ocurrió, por otro lado, con otros muchos documentos coetáneos aprobados como él al amparo del Estatuto Municipal (Quirós Linares, 1985, pp. 95-96).

De hecho, el expediente estuvo paralizado hasta 1948, cuando el plano fue expuesto al público para cumplir con uno de los trámites de obligado cumplimiento previstos en el Estatuto Municipal, obviado hasta ese momento. La exposición pública duró treinta días, pasados los cuales, y sin que nadie presentara objeción alguna, el proyecto fue aprobado de manera definitiva por el ayuntamiento. El Consistorio comunicó asimismo a la Sección de Urbanismo de la Delegación Provincial de Oviedo su pretensión de que el plano fuese actualizado y se incorporasen a él las escasas novedades urbanísticas surgidas desde 1935, la mayor parte de ellas relacionadas con las obras del ferrocarril Ferrol-Gijón ${ }^{11}$. Desconocemos si esta petición fue finalmente aceptada, aunque la ausencia de documentación al respecto en el archivo municipal nos hace pensar que no fue tenida en cuenta.

Durante los años posteriores a la aprobación del proyecto de ensanche la prolongación de la penuria económica tuvo como consecuencias inmediatas la práctica paralización del crecimiento demográfico, inferior a doscientas personas (Murcia Navarro, 1981, p. 278), y también del espacial. En estas adversas condiciones la disponibilidad de un documento de planeamiento como el ensanche era innecesaria y su incidencia sobre el desarrollo del plano prácticamente nula. La actuación más importante acometida en esta época, prevista en el proyecto, fue la apertura de la calle José Tartiere y la prolongación de la de Las Armas con el fin de dividir una de las manzanas de gran tamaño. También se ejecutó, conforme

\footnotetext{
11 AMN, expediente 554.7: Expediente de plano de población y ensanche o plan general de ordenación urbana de la villa de Navia.
}

a lo establecido tres décadas antes, el alargamiento de la calle San Francisco; si bien en este caso la apertura se hizo con distinto motivo del planeado en origen: dar acceso a los bloques de viviendas promovidos por el $\mathrm{Pa}$ tronato Francisco Franco al este de la localidad ${ }^{12}$.

Curiosamente, a pesar del estancamiento de la construcción, las escasas promociones de viviendas realizadas en esta época no respetaron las alineaciones del proyecto de ensanche y fueron ejecutadas fuera de los límites urbanos señalados en el mismo. Así ocurrió, por ejemplo, con el grupo de viviendas de El Pardo y un segundo grupo construido en San Francisco, puesto que a pesar de ser de iniciativa pública fueron levantados al norte de la Olga y al este de la calle III, eje exterior del ensanche, respectivamente.

La atonía urbanística mantenida a lo largo de toda la posguerra sólo pudo superarse a partir de 1959, una vez aprobado el Plan de Estabilización. Éste supuso el inicio del resurgir económico de todo el país y también el del concejo naviego, que vio cómo en los años posteriores se instalaron en él algunas empresas fabriles de cierto tamaño. La primera lo hizo en 1961, fue la láctea Reny Picot, que había construido su fábrica en el valle de Anleo. Al principio se caracterizó por su modesto tamaño y su elevada especialización en unos pocos productos, pero pronto se diversificó al tiempo que aumentaba la producción y acometía nuevas ampliaciones (Sevilla Álvarez, 2009, pp. 172-177). La segunda empresa en llegar fue Astilleros Armón, que abrió sus instalaciones en 1965 entre la Olga y la dársena, justo al norte del núcleo urbano ${ }^{13}$. Estas empresas fueron, probablemente, las principales causantes del cambio experimentado por el ritmo del crecimiento demográfico de Navia durante los años posteriores ${ }^{14}$, superior al de otras villas próximas y también al que ella misma había tenido en las décadas precedentes. Con todo, inferior al que treinta años antes había previsto José Martín Elvira ${ }^{15}$.

\footnotetext{
12 AMN, caja 340: Entrevista con Fernando Beltrán Rojo, gerente del Patronato Francisco Franco. S/f. La prolongación de la calle favoreció asimismo la construcción del Hogar-Asilo Santa Rita, abierto en 1955 en San Francisco gracias al legado del matrimonio Francisco Rodríguez González y Rita Villaret Sordo. El edificio estaba destinado al «sustento, habitación, vestido y servicios médicos y farmacéuticos, de ancianos y enfermos desvalidos de ambos sexos nacidos en el Concejo de Navia y si fuera posible en el de Boal» (Martínez Fernández, 1967, p. 160, n. 92).

13 En 1973, fuera ya de nuestro periodo de estudio, se inauguró la fábrica de pasta de papel de CEASA, aguas arriba de la ría.

14 Otro factor de crecimiento fue la construcción del embalse de Arbón entre 1962 y 1967 (Madrazo Feliú, 1981, pp. 95-99)

${ }^{15}$ Entre 1960 y 1970 Navia pasó de 1.722 a 2.156 habitantes (Murcia Navarro, 1981, p. 278)
} 


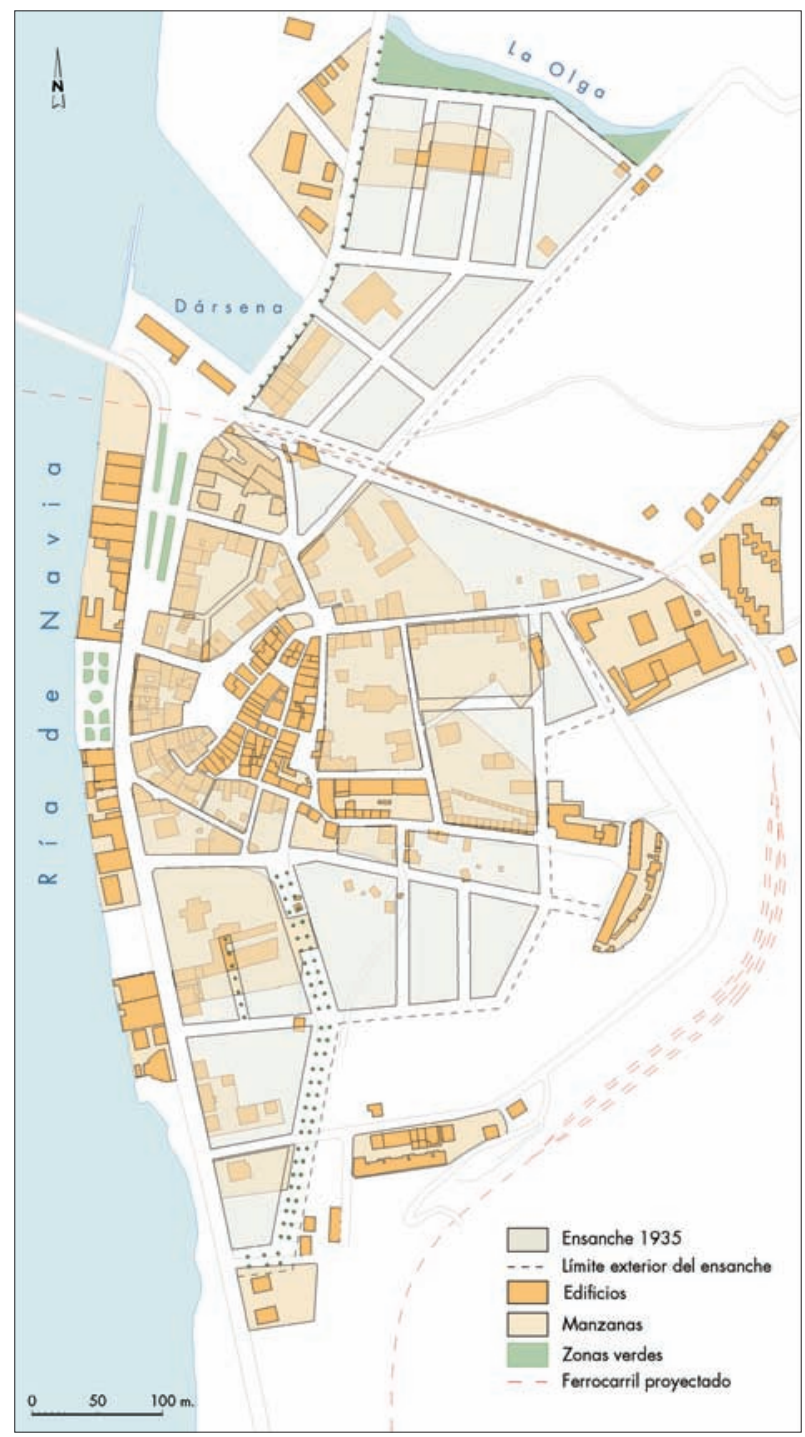

Fig. 8. Plano de la villa de Navia de 1968. Elaboración propia a partir de la cartografía del Plan General de Ordenación Urbana de Navia de 1968 incluida en García Fernández (1979); memoria y perfiles longitudinales del Plano de población y ensanche de la villa de Navia (1934); cartografía catastral actual; mapa topográfico del Principado de Asturias escala 1:5.000 (2005-2006), hojas 110406 y 110407; fotografía del año 1970, vuelo de la Diputación (1969-1970), fotograma 6050, Cartoteca del Principado de Asturias (copia facilitada por el Observatorio del Territorio, Departamento de Geografía de la Universidad de Oviedo); fotografía del año 1983, vuelo interministerial (1983-1986), fotograma 3801, Cartoteca del Principado de Asturias (copia facilitada por el Observatorio del Territorio, Departamento de Geografía de la Universidad de Oviedo).

El crecimiento de la población reactivó con rapidez la construcción de viviendas que ahora, favorecida por el aumento de la renta per cápita, estuvo impulsada por la iniciativa privada. Sin embargo, esta mejora en el ritmo constructivo no implicó la apertura de nuevos viales; la mayor parte de los nuevos edificios se levantó en los solares que todavía estaban vacantes en el interior del casco, o bien en los límites del ensanche ${ }^{16}$.

Consecuencia de lo expuesto era que en esta época la ocupación del ensanche apenas se había iniciado. En su parte septentrional la única excepción eran algunas naves industriales construidas en las inmediaciones de la dársena, y en la meridional la mayor parte de los nuevos edificios se concentraban en la parte más próxima al casco histórico.

A finales de la década de 1960, por tanto, el ensanche de 1934 había dejado una huella muy escasa en el plano de Navia, fundamentalmente porque el escaso crecimiento de la localidad había obviado la necesidad de abrir viales y consolidar nuevas manzanas. Pese a ello, el Plano de población y ensanche de 1934 dejó de estar vigente en 1970, en el momento en el que la Corporación municipal aprobó un nuevo documento urbanístico para sustituirlo. Éste sería el primer Plan General de Ordenación Urbana, concluido en 1968 y nacido en este caso al amparo de la ley del Suelo de 1956, que ya recogía algunos postulados de la Carta de Atenas y propugnaba la implantación de un modelo urbano bien distinto al vigente hasta ese momento.

La implantación de las nuevos postulados urbanísticos, las amplias necesidades de suelo previstas para usos como el turístico o el industrial y la necesidad de reordenar el cada vez más intenso tráfico rodado son algunas de las causas que llevaron al ayuntamiento, en consonancia con lo ocurrido en otros muchos municipios españoles, a la redacción del proyecto.

\section{CONCLUSIONES}

Las optimistas previsiones económicas y demográficas para la villa, unidas a la promulgación en los años veinte del Estatuto Municipal, permitieron que Navia, pese a su modestia, contase con un ambicioso proyecto de ensanche y reforma interior mediada la década de 1930. Lo tardío de su aprobación lo convierte en uno de los últimos proyectos de expansión urbana realizados en Asturias conforme a los principios urbanísticos vigentes en la centuria anterior; principios que a partir de

\footnotetext{
16 La más importante de estas promociones inmobiliarias fue la construcción por parte de la Electra de Viesgo de catorce viviendas para sus trabajadores en el barrio de San Roque (Martínez Fernández, 1967, p. 169).
} 


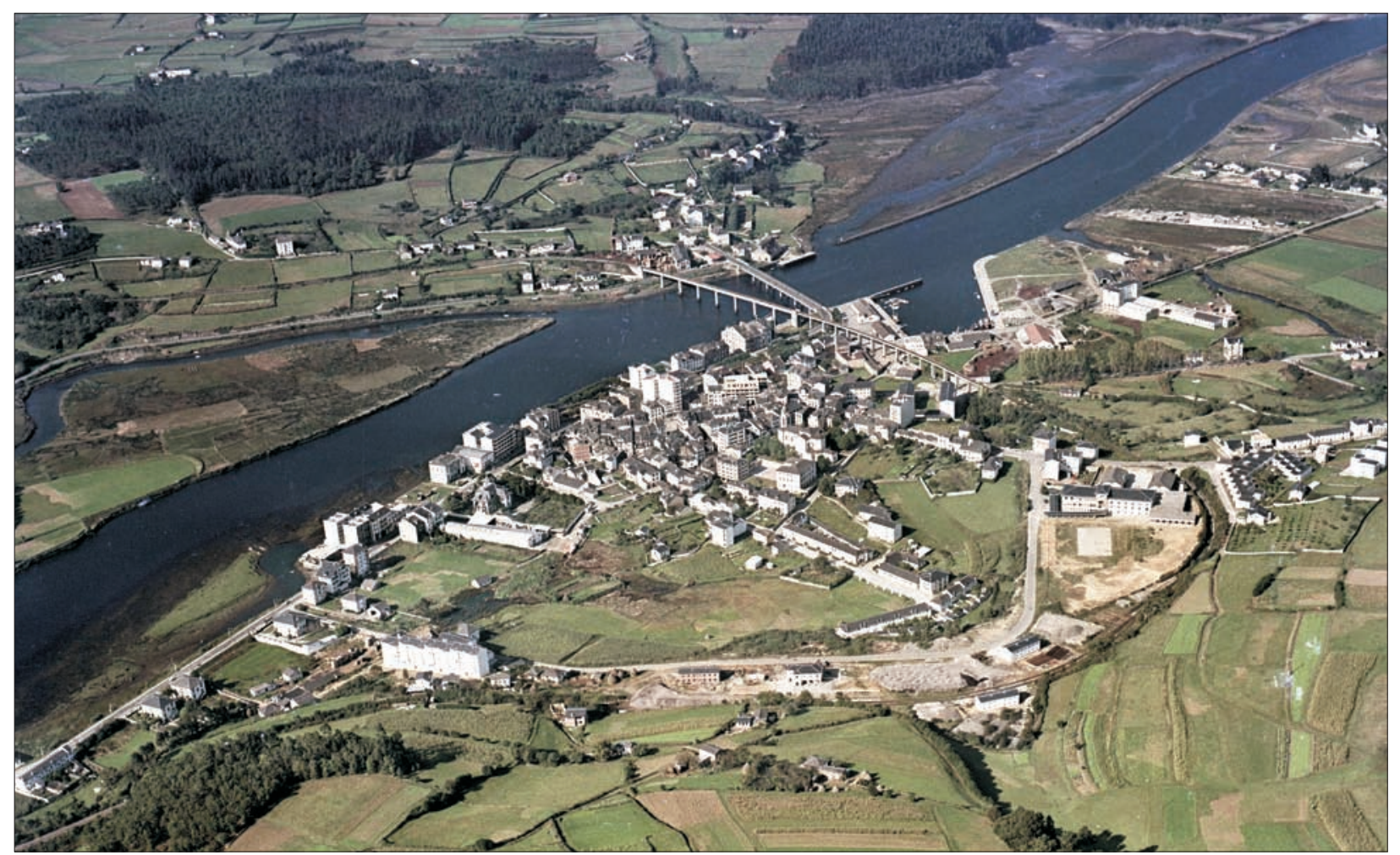

FIG. 9. En 1971 todavía era evidente el emplazamiento original de Navia sobre una elevación situada en la margen derecha de la ría. Desde fines del siglo XIX la expansión tuvo un carácter longitudinal siguiendo la línea marcada por la nueva carretera de Oviedo. El crecimiento posterior, sin embargo, se dirigió hacia el este, por donde discurriría el ferrocarril, y hacia el nordeste. FOAT, 1971. Muséu del Pueblu d'Asturies.

entonces irán siendo sustituidos, lenta pero progresivamente, por los impulsados por la Carta de Atenas, cuya aplicación dará lugar a un nuevo modelo de ciudad, bien distinto al que se derivó de la aplicación de las leyes de ensanche.

Pero la existencia de ese proyecto de urbanización que estuvo vigente durante algo más de treinta años ha dejado una huella muy limitada en el plano actual de Navia. Primero, porque la guerra civil y su secuela de la posguerra, un periodo de grave recesión en toda España y por ende en el concejo naviego, frenaron el crecimiento demográfico y el desarrollo urbano y, en consecuencia, la ocupación del ensanche proyectado por el ingeniero José Martín Elvira. Y más tarde, a partir de los años sesenta, porque aun cuando sí se produjo una cierta expansión urbana, ésta se hizo sin tener en cuenta lo proyectado en el Plano de población y ensanche de la villa de Navia; en parte porque éste fue sustituido, como documento director del urbanismo naviego, por el primer Plan General de Ordenación Urbana del concejo aprobado en la temprana fecha de 1970.

\section{BIBLIOGRAFÍA}

Acevedo y Huelves, B. (1900): «Navia y Villayón», en O. Bellmunt y F. Canella: Asturias. T. III, pp. 326332.

Álvarez Suárez, E., y F. M. Gámez. (1923): Asturias: guía monumental, histórica, artística, industrial, comercial y de profesiones. Mateu, S. L., 571 pp.

Bassols Coma, M. (1973): Génesis y evolución del derecho urbanístico español (1812-1956). Montecorvo, Madrid, $638 \mathrm{pp}$.

Cuenca Busto, C., M. F. Fernández Gutiérrez y J. Hevia BlanCO (2003): Escuelas de indianos y emigrantes en Asturias: rehabilitación de las escuelas de Vidiago. Ediciones Trea, Gijón, 245 pp.

Fernández Méndez, S. J. (2002): Astilleros Armón: 500 buques construidos. Five hundred vessels built. Astilleros Armón, Navia, 271 pp.

GarCía FernÁNDEZ, E. (1979): Adaptación del plan de ordenación urbana de Navia. Ayuntamiento de Navia, Navia, 114 pp. 
Junceda, E. (1936): Topografía médica del concejo de Navia (Asturias). Cosano, Madrid, 145 pp.

Madrazo Feliú, B. (1981): Electra de Viesgo. 75 años. Electra de Viesgo, Santander, 190 pp.

Martínez FernándeZ, J. (1965): «Navia remota y actual. Datos y referencias para su historia. Siglo XIX: el final de un letargo». Boletín del Instituto de Estudios Asturianos, núm. 56, pp. 135-196.

- (1967): «Navia remota y actual. Datos y referencias para su historia. I. Siglo xx (primera parte): calendario de sucesos». Boletín del Instituto de Estudios Asturianos, núm. 60, pp. 113-172.

- (1986): Navia medieval. Instituto de Estudios Asturianos, Oviedo, 160 pp.

- (1987): Calles y plazas de Navia (breve noticia de su historia y de sus nombres). Navia, $31 \mathrm{pp}$.

Méndez GarcíA, B. (1992): «El bajo Navia: Navia, Coaña y Villayón», en Geografía de Asturias. T. II, Editorial Prensa Asturiana, Oviedo, pp. 261-280.

- (1993): La marina occidental asturiana. Oikos-Tau, Vilassar de Mar, 565 pp.

- y G. Morales Matos (1991): «Transformaciones espaciales en las villas costeras occidentales de Asturias: Castropol, Figueiras, Tapia, A Caridá, Navia y Puerto Vega», en Sociedad y territorio. XII Congreso Nacional de Geografía. Pp. 553-560.

Murcia Navarro, E. (1981): Las villas costeras en el sistema urbano asturiano. Silverio Cañada, Gijón, 495 pp.

Navia-Osorio y Castropol, L. De, y J. L. Pérez de CAsTRO (1976): Datos para la historia del concejo de $\mathrm{Na}$ via. Oviedo, $455 \mathrm{pp}$.

Peribáñez CavedA, D. (1992): Comunicaciones y comercio marítimo en la Asturias preindustrial (17501850). Gijón, 355 pp.

Quirós Linares, F. (1985): «El proyecto de ensanche de Pola de Siero de 1932». Ástura. Nuevos Cartafueyos d'Asturies, núm. 3, pp. 95-96.

Reglamentos para la ejecución del Estatuto Municipal aprobados por los reales decretos de 2, 10 y 14 de julio y 22 y 23 de agosto de 1924 (1924). Reus, Madrid, 215 pp.

Ruiz de LA PeÑA, J. I. (1981): Las «Polas» asturianas en la Edad Media: estudio y diplomatario. Universidad de Oviedo, Departamento de Historia Medieval, Oviedo, 446 pp.
- M. S. Beltrán SuÁrez y M. Álvarez Fernández (2006): «Las villas nuevas de Asturias: siglos XIIXIV». Boletín Arkeolan, núm. 14, pp. 115-138.

Sevilla Álvarez, J. (2009): La industria láctea en Asturias. Muséu del Pueblo d'Asturies, Gijón, 302 pp.

TeCnia (2015): Catálogo urbanístico del concejo de Navia. Documento de aprobación inicial.

TERÁN, F. (1999): Historia del urbanismo en España, III. Siglos XIX y XX. Cátedra, Madrid, 397 pp.

\section{FUENTES DOCUMENTALES}

ArChivo MUNicipal de NAVIA

96-Plan de ordenación urbana - Gráfico del movimiento demográfico del municipio desde 1920 a 1965.

340-Entrevista con Fernando Beltrán Rojo, gerente del Patronato Francisco Franco. $S / f$.

554.7-Expediente de plano de población y ensanche o plan general de ordenación urbana de la villa de Navia.

554.10-Expediente del Plan General de Ordenación Urbana de la villa de Navia en 1968.

557.59-Expediente de contratación para la redacción del plano de población y ensanche o plan general de ordenación urbana de la villa de Navia (1932-36).

\section{FUENTES CARTOGRÁFICAS}

\section{CARTOGRAFÍA CATASTRAL ACTUAL}

Mapa topográfico del Principado de Asturias escala 1:5.000 (2005-2006).

\section{FUENTES FOTOGRÁFICAS}

Fototeca del Muséu del Pueblu d'Asturies.

Fototeca del Observatorio del Territorio, Departamento de Geografía de la Universidad de Oviedo.

\section{RECURSOS ELECTRÓNICOS}

$<$ http://www.occidente.com/navia/villa.htm>. 